Weeds, Weeds, Weeds

By Sir Charles Vernon Boys. Pp. 72. (London: Wightman and Co., Ltd., 1937.) 1s. net.

THIs charming little book relates the practical experiences of a very keen observer in eradicating by various methods the common weeds of his farms and gardens.

The earlier pages deal wiuh lawns; the standard lawn sands have proved highly successful, but Sir Charles may have been a little more fortunate than other gardeners on chalk soils, where eradication of weeds from lawns is frequently difficult. A recipe for lawn sand would perhaps help readers who desire to make their own mixtures.

The author has thoroughly tested sodium chlorate as a weed killer against nettles and many other plants, and he recommends its use on drives and paths. He carefully points out the fire danger, and how it may be avoided. The reviewer has seen sodium chlorate effect a thorough clearance of some thousands of the lesser bindweed, pushing up through the surface of a newly made hard tennis-court. Care must be used to avoid any undesirable firework displays during subsequent play! By the liberal use of the hose the chlorate can be washed down below the granite chips, which dry rather slowly when the chlorate is used. Recent letters in The Times show the potency of this chemical in eradicating the troublesome Aegopodium podagraria L., well known as goutweed, or bishopsweed as it is inappropriately called, for bell, book and candle fail to exorcise it. The author well deserves to be free from such a diabolical weed; there is but brief mention of it.

There are many other practical hints of great value to the gardener concerning humus, monkey jacks and tools. Only a few generic names, for example, Plantago, escape a capital letter. This book is truly wonderful value at the price.

M. A. H. T.

Borderlands of Language in Europe :

and their Relation to the Historic Frontier of Christendom. By Vaughan Cornish. Pp. $x+105$. (London: Sifton Praed and Co., Ltd., 1936.) 6s. net.

As an exponent of human geography, Dr. Vaughan Cornish is always stimulating. In the present study, he deals with the debatable borderlands of Europe. As the result of an examination of linguistic frontiers, in which he has traced their history backward, he has in almost every instance been able to arrive at a definite date of origin for such borderlands. This he finds falls within the period when the district under investigation was situated on the frontiers of Christendom. In the west, these linguistic boundaries perpetuate conditions in the political geography of Europe at the time of the collapse of the Western Empire. Thus, for example, the line of demarcation between French and German near Belfort follows the line of the political frontier between Christian Burgundians and heathen Alamannians in the fifth and sixth centuries; while an even more striking instance of the politico-religious frontier is to be seen in the German-speaking population of the Italian province of Alto Adige, who are the survivors of heathen Bavarians who crossed Rhaetia and retained their pagan customs in the mountains until 730 . The like argument is applied to the linguistic frontiers of eastern Europe. For these studies the author stresses the importance of the ecclesiastical map of medieval Europe, which is brought out most clearly in his examination of conditions in Bosnia, as a borderland of nationality and race, where peoples of the same language joined different churches.

\section{Biology for Medical Students}

By C. C. Hentschel and Dr. W. R. Ivimey Cook. Pp. xii +664 . (London, New York and Toronto : Longmans, Green and Co., Ltd., 1937.) 18s. net.

THE second edition of this well-known text-book has been modified to cover the joint syllabus of biology for medical students adopted by the Universities of Oxford and Cambridge, as well as to satisfy the students in the University of London. This has involved descriptions of Fucus and several green algæ, Peronospora among the fungi and the cockroach as an example of an insect.

Apart from these additions, the whole text has been revised and brought up to date.

In spite of the syllabuses, however, the text seems to contain too much for a medical student to grasp in his first year, for he is not studying the subject as a biologist but rather as an aspirant to different ends, using biology as a basic science to his more specialized and more relevant studies. This applies especially to the chapter on evolution and heredity.

The book, however, is well written and as such would form a very desirable introduction for students of biology itself. But while medical students are forced to read such (to them) detailed material in their first year, it is no wonder that the majority of them dislike the subject and ask why they should suffer it.

Systèmes de référence et mouvements (physique classique)

Par Prof. Augustin Sesmat. 5: L'Optique des corps au repos. Pp. 365-484. 18 francs. 6 : L'Optique des corps en mouvement. Pp. 485-614. 20 francs. 7 : L'Esprit de la science classique. Pp. 615-688. 12 francs. (Actualités scientifiques et industrielles, 483-485.) (Paris: Hermann et Cie., 1937.)

The issue of parts 5, 6 and 7 completes the above volume in this series on classical physics; it is to be followed by one dealing with relativity physics. The present parts cover pre-Fresnel optics, the general theory of wave motion, the electromagnetic theory of Maxwell and the electronic theory of Lorentz, the influence of movement of the source or of the medium on the propagation of light, the drag of the medium, the experiments to test the theories, including those of Michelson, the origin of the idea of action at a distance, material points and their relations, physical time and simultaneity, relativity in physics. The volume concludes with a bibliography of ten pages. 